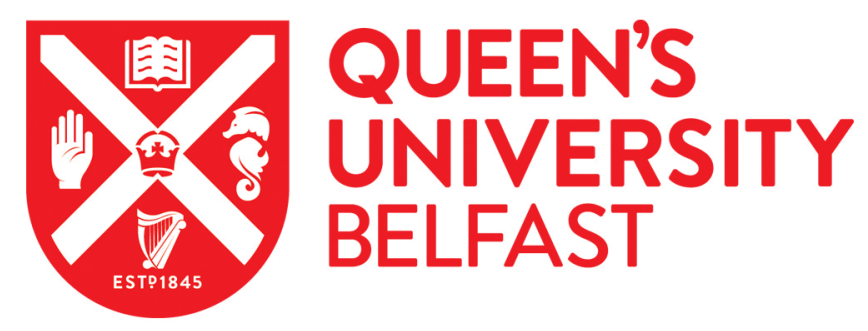

\title{
Informal Relationships and De Facto Independence of the Regulator in the Irish Telecommunications Regulatory Arrangement
}

MacCarthaigh, M. (2014). Informal Relationships and De Facto Independence of the Regulator in the Irish Telecommunications Regulatory Arrangement. In D. Aubin, \& K. Verhoest (Eds.), Multi-level regulation in the telecommunications sector: Adaptive regulatory arrangements in Belgium, Ireland, the Netherlands and Switzerland (pp. 78-107). Palgrave Macmillan. http://www.palgrave.com/page/detail/multilevel-regulation-in-thetelecommunications-sector-david-aubin/?K=9781137004918

Published in:

Multi-level regulation in the telecommunications sector: Adaptive regulatory arrangements in Belgium, Ireland, the Netherlands and Switzerland

\section{Document Version:}

Peer reviewed version

\section{Queen's University Belfast - Research Portal:}

Link to publication record in Queen's University Belfast Research Portal

\section{Publisher rights}

Muiris MacCarthaigh, Informal Relationships and de Facto Independence of the Regulator in the Irish Telecommunications Regulatory Arrangement, from 'Multi-Level Regulation in the Telecommunications Sector' (c) 2014, Palgrave MacMillan, reproduced with permission of Palgrave Macmillan'.

This extract is taken from the author's original manuscript and has not been edited. The definitive, published, version of record is available here: http://www.palgrave.com/page/detail/multilevel-regulation-in-the-telecommunications-sector-david-aubin/?K=9781137004918

\section{General rights}

Copyright for the publications made accessible via the Queen's University Belfast Research Portal is retained by the author(s) and / or other copyright owners and it is a condition of accessing these publications that users recognise and abide by the legal requirements associated with these rights.

\section{Take down policy}

The Research Portal is Queen's institutional repository that provides access to Queen's research output. Every effort has been made to ensure that content in the Research Portal does not infringe any person's rights, or applicable UK laws. If you discover content in the Research Portal that you believe breaches copyright or violates any law, please contact openaccess@qub.ac.uk. 
Chapter 4

\title{
INFORMAL RELATIONSHIPS AND DE FACTO INDEPENDENCE OF THE REGULATORIN THE IRISH TELECOMMUNICATIONS REGULATORY ARRANGEMENT (10,101 WORDS, 39 P.)
}

\author{
Muiris MacCarthaigh ${ }^{1}$
}

\subsection{Introduction}

As with the other jurisdictions considered in this volume, the Irish state's administrative apparatus has performed a variety of social and economic regulatory functions for many years. A rapid and comparatively recent increase in the use of independent national regulatory agencies (NRAs) between 1990 and 2010, however, increased the complexity of the Irish regulatory environment and presented new governance and co-ordination challenges. The work and organisation of these new NRAs have been strongly influenced not only by the EU and domestic actors such as the courts, but also by the Irish politicoadministrative regime and culture. Drawing on an analysis of the Irish regulatory arrangement for telecommunications, the focus of this chapter is on the primary Irish telecoms regulator - ComReg - and in particular how the use of informal powers and influence have been deployed to meet the challenges of regulating a rapidly-changing policy sector. 
Beginning with a brief theoretical examination of the role of informality in bureaucracy, the chapter proceeds by suggesting that informality can be considered along two dimensions, namely, discretionary behaviour and involvement in networks respectively. Following this, a description of the Irish politico-administrative system and the background to the liberalization and regulation of the telecommunications sector is presented. As part of this analysis, the actors in the regulatory environment and the formal and informal relationships between them are mapped. Adopting an analysis founded on original and secondary sources, the chapter finds that as well as the formal regulatory arrangement, telecoms regulation in Ireland continues to be strongly informed and characterized by informality and informal relationships.

\subsection{The role of informality and informal relationships within}

\section{bureaucracies}

It is well documented that within small states public administration organizations and public servants must develop increased capacity to multi-task (Katzenstein 1985; Baker 1992; Randma-Liiv 2002). This is particularly the case for those states in the AngloSaxon administrative tradition, where the generalist system of recruitment and appointment allows for considerable mobility of bureaucrats between tasks as priorities change, and a demonstrated capacity to successfully undertake different roles is frequently a requirement for career advancement. The size of the bureaucracy and political system in small states also determines that personal contacts are valued professionally, and it is comparatively easy for public servants to communicate directly through informal personal contacts and networks across the administrative system. 
Alongside the role played by scale in determining the manner in which an administrative system operates is the type of organizational culture which exists within it. Organizational culture is concerned with the informal norms and values that are important for the activities of organizations (cf. Scott 2001; Christensen et al. 2007). What makes an action appropriate in a certain organization is a normative and institutional foundation that varies across organizations depending on how their respective cultures have evolved, and what its dominant norms and values are. Therefore, while all bureaucratic systems are concerned with legality and formal rule-following, there will be some variation across bureaucratic systems in the degree to which their organisational culture also tolerates the use of informal methods for communicating and ensuring the performance of tasks (cf. Hofstede 2001).

In the Irish case, which is the focus of this chapter, organizational culture within the bureaucracy has traditionally placed an emphasis on the avoidance of conflict and problem solving through the use of informal channels and networks². Such networking also provides a means for overcoming departmentalism and reducing transaction costs, as well as developing trust and shared identity through frequent interaction and exchange. A review of the Irish public service by the OECD in 2008 noted that 'the Irish Public Service is already rich with informal networks that reflect the small size of the country and of the Public Service' and that 'Ireland is a small country with informal ties between departments and agencies, and between politicians and citizens' (OECD 2008: 44, 229). Thus informality is recognized as a defining characteristic of the Irish administrative system and supported as a modus operandi. 
Given its potential range of application, however, the concept of informality is inherently problematic to theorise or model. Misztal defines it in sociological terms as 'a form of interaction among partners enjoying relative freedom in interpretation of their roles' requirements' (2000:8). By contrast Helmke and Levitsky view the concept more narrowly by looking at informality in institutional terms, defining it as 'socially shared rules, usually unwritten, that are created, communicated, and enforced outside officially sanctioned channels' (2006: 5). In policy terms, informality could range from the actual setting aside of formal rules in the pursuit of objectives, for example, to the development of standard procedures where none exist. Informality can even be conceptualized as simply corruption or participation in illegal activities, networks or relationships. This latter view, for example, has long been of interest to political scientists concerned with how informal behaviour can undermine formal institutions. For the purposes of this paper, however, we consider informality more narrowly and along two related dimensions: the use of discretion in the implementation of policy, and the engagement of actors in non-formal (but rule-bound) networks and communications.

In relation to the first dimension, the use of discretionary behaviour by bureaucrats when making decisions, and particularly those at 'street level', is a wellrehearsed concern in administrative law (cf. Lipsky 1980; Hawkins 1992). To its proponents, it is an accepted means of blunting the potentially harsh nature of pure rational law. In this perspective, informality includes the extension of autonomy to bureaucrats to implement a law in accordance with principles established in a political arena for that law, and based on values deemed appropriate to the public interest. By definition, this is a discretion enjoyed by most regulators in performing their standard- 
setting and decision-making roles, and is of particular importance in rapidly changing policy sectors which cannot be regulated by strict legislative interpretation alone.

In relation to the second dimension, the concern is the capacity of actors (or in this case regulatory authorities), to engage in a variety of non-formal networks and personal communications, and to use their informational and resource advantages within such networks in the pursuit of their remit. This is in keeping with Hood's (1983) seminal identification of Nodality (or positioning within a network) as a generic type of instruments utilized by governments to fulfil tasks (the others being Authority, Treasure and Organization). In this perspective, an organization can exercise not alone its formal authority but also any opportunities for discretionary engagement in networks. Such networks can typically emerge organically in response to particular needs and issues, and though informal in nature, each member is bound by their respective organizations' rules.

At first glance, the suggestion of engagement in informal networks or communications may appear unusual in a regulatory setting where transparency is central to market and stakeholder confidence. However the importance of culture, informality and interdependent relations between actors in determining a regulatory regime were key findings of the study by Hall et al (2000) of the British telecommunications regime. In that case, they found that the incumbent operator was able to exert formal and informal influence on the regulator, and recorded the close monitoring by the parent Ministry of the regulator's activities in spite of the formal separation of jurisdictions. They concluded that these factors were as important as instrumental considerations in shaping the regulator’s decision-making processes. 
The use of such informal methods in order to engage and persuade others (or more specifically regulatees) is also consistent with the less interventionist enforcement methods identified by Ayres and Braithwaite in their scheme of regulatory enforcement (1992: 35). In a pyramidal model, they identify negotiated and self-regulatory modes of regulation (at the base of the pyramid) as most desirable form, but recognize that it is only likely to occur in the presence of the threat of imposed external regulation - the apex of the regulatory 'enforcement pyramid'. Thus informal communications and engagements can support effective self-regulating regimes, and reduce the need for the more litigious ‘adversarial legalism’ which Kagan (2001) describes as permeating the American regulatory and policy process. Non-formal networks can therefore be utilized successfully within legal and constitutional frameworks to support rather than undermine the achievement of formal tasks and objectives. And as will be demonstrated in the casestudy below, as well as remaining subsidiary to formal processes, informal practices and networks can also be formalized once their utility becomes accepted and established. To elaborate on these themes, we turn here to consider the emergence of the Irish telecoms regulatory regime, and in particular to extent to which informality has played a role in its development.

\subsection{The Irish administrative system and the liberalisation and}

\section{regulation of telecommunications}

The Republic of Ireland (hereafter Ireland) is a unitary state of 4.5 million people employing a system of representative parliamentary democracy. It has a legal tradition of the public interest model with its roots in the English common law system. Irish law 
(including administrative law) draws on a combination of the 1937 Constitution, EU law, statute law and judicial decisions. The core units of administrative organization are government departments staffed by civil servants, of which there are normally fifteen, each headed by a government Minister including the Taoiseach (Prime Minister). These ministers, along with a small number of office holders, collectively form the Cabinet which normally meets weekly and is the principal decision-making body in the state. Ireland adheres to a doctrine of ministerial accountability to parliament, and in theory all public organisations are primarily held politically accountable to parliament via the Minister responsible for their 'parent' department.

As a former British colony, the Irish administrative system shares many features in common with the Whitehall system, in which the civil service is generalist and explicitly non-political, with civil servants precluded from joining political parties (Rhodes, Wanna and Weller 2009). Traditionally, the role of top civil servants has been to provide impartial advice and policy options to government, though in practice a wider range of actors are involved. There is considerable emphasis on cooperation at the political-administrative interface and resignations of senior civil servants (and Ministers) are rare. Ireland remains close to the model of career-based recruitment to the bureaucracy, and traditionally there have been very few external appointments to its more senior levels, preserving a relatively conservative administrative culture with shared norms and values.

In relation to the telecommunications sector, and in line with broader questioning of monopolist structures at the European level, the Irish Government took its first steps towards liberalization of the telecoms market in the 1980s. Under the terms of the Postal 
\& Telecommunications Services Act 1983,responsibility for provision of the Irish state's postal and telecommunications services were transferred from the Department of Posts and Telegraphs (which had existed since 1924) to two newly-created state enterprises An Post and Bord Telecom Éireann. Both came into being on the 1 January 1984. In this first step the telecommunications market was corporatized but not liberalized: both companies still held monopoly positions in the postal and telecommunications markets respectively, and their Boards were answerable to the Minister as shareholder. Bord Telecom Éireann created a subsidiary company called Eircell in 1984, which developed Ireland's first mobile telephone network in 1986, and later its first digital (GSM) network in 1993. Simultaneously, a new Department of Communications was created. This Department assumed responsibility for the remaining functions of the Department of Posts and Telegraphs as well as the Department of Transport, which were both abolished.

During the 1990s, successive Irish governments sought to open up electronic communications networks and services to promote competition with a view to improving Ireland's economic competitiveness by upgrading Ireland's communications network. The first steps in the liberalization process in Ireland were taken as a result of the 1988 EU Terminal Equipment Directive (88/301/EEC). Services other than the public provision of voice telephony were subsequently opened to the market in 1990, under influence of Directives 90/387 CE (Open Network Provision Directive, the so-called ONP directive) and 90/388 CE (on competition provisions). The Leased Lines Directive (Council Directive 92/44/EEC) obliged Member States to provide applicants with a minimum and equal set of leased lines for use or resale from 5 June 1993 onwards (Massey and Shorthall 1999). 
In 1994, prompted by these developments at European level, a Telecommunications Strategy Group was established by the Irish Government to examine the telecommunications sector in Ireland and to advise it on the establishment of an independent regulatory agency for the sector. The report of this Group led to the creation in Office of the Director of Telecommunications Regulation (ODTR). In March 1996, the Commission (under the terms of Commission Directive 96/19/EC) removed all remaining restrictions on competition in telecommunications services, and the telecommunications market was opened up to full competition on 1 January 1998.

Ireland sought and achieved a partial derogation from the Directive (which interviews reveal was supported by the incumbent operator) until 1 January 2000. This was necessary in respect of the proposed liberalization of voice telephony services which required considerable restructuring within Telecom Éireann, as well as more general development of Ireland's telecommunications network. It was also necessary to put in place a licensing framework for new operators, a fair telephone numbering system and to review the rights and obligations governing interconnection between (the former monopolist) Eircom's telecommunications network and the facilities of other operators. In the event, this work was expedited quickly and the ending of this derogation was brought forward to 1 December 1998.

In advance of the full telecoms market liberalization in Ireland, on the 30 November 1998 the Director of Telecommunications Regulation awarded twenty-nine new telecommunications licenses. Also prior to liberalization, in the case of mobile telephony, Telecom Eireann's monopoly was ended when a second GSM mobile operator (ESAT Digifone) was introduced in 1996 following public competition organized by the 
then Department of Public Enterprise ${ }^{3}$, and a third (Meteor) in 1998. In 1999 Telecom Éireann was privatised by way of a public share offering, and its name changed to Eircom. Though its ownership has changed hands on several occasions since then, it remains the largest operator in the telecommunications market in Ireland.

The reform agenda in Ireland after 1998 primarily focused on the liberalization and opening of domestic markets to competition (ODTR 2000: 2), in line with European Union priorities. The second priority of the Union, the harmonization of the conditions of access to public telecommunications networks in Member States, was less of a concern. Particular focus was given to regulating the conduct of the former monopoly provider Eircom and its mobile subsidiary Eircell. However, the Office of the Director of Telecommunications Regulation noted that weaknesses in the legislation underpinning its work meant that all of its decisions were open to legal challenge (ODTR 2000: 7).

As the number of NRAs created by government expanded rapidly during the 1990s, the then Department of Public Enterprise (which had responsibility for electricity, gas, aviation and telecommunications) produced a series of proposals concerned with balancing the governance and accountability requirements of regulatory bodies (Department of Public Enterprise 2000). In part, the review was also prompted by the refusal of the first Director of Telecommunications Regulation to appear before a parliamentary committee, citing the absence of a formal requirement in the legislation establishing her office for her to do so. One of the main proposals recommended by the review was the use of sectoral (rather than industry specific or supra-sectoral) regulators, comprised of three persons ('commissioners') who would be formally appointed by the Minister. This proposal, along with several others contained in the report, was 
implemented through the Communications Regulation Act of 2002 which established ComReg, the successor of the ODTR (below).

In April 2002, the EU Council of Ministers adopted a package of legislative proposals designed to modernize and harmonize the Community's legislation on electronic communications ${ }^{4}$. The legislation concerned such issues as Access and Interconnection; Universal Service and User Rights, and Data Protection. In Ireland, the new EU package was transposed on 25 July 2003. The Irish regulations transposing the Directives created a framework of obligations and remedies, an appeals body, and enforcement mechanisms for the communications sector.

While Ireland is a signatory of the WTO Basic Telecommunications Agreement, its telecommunications regulation laws in this area have remained primarily based on EU Directives as well as national laws (particularly under the Wireless Telegraphy Act of 1925). This legal framework, within which ComReg operates, is determined by Directives of the European Council and Parliament, as well as 'soft law' from the Commission and the ERG (which has since 2010 become BEREC) (Connery and Hodnett 2009: 225, 234). Irish law in this field of regulation has remained EU rather than domestically derived.

\subsection{Regulatees in the current market}

The telecoms infrastructure, wholesale and retail markets in Ireland are dominated by a number of large international companies. They include Vodafone, O2, Eircom (STT), '3' (Hutchinson Whampoa), BT and UPC. Figure 4.1 below identifies that the incumbent Eircom still controls a large portion (almost 2/3) of the market. Figure 4.2, however, 
identifies that the dominance of Eircom in fixed line infrastructure services continues to decline, with a gradual reduction in its market share between 2008 and 2012.

<insert figure4.1 around here >

<insert figure4.2 around here $>$

\subsection{The Irish telecommunications regulator: ComReg}

The Irish experience of telecoms liberalization had a number of influences. Of course, the Ireland was profoundly influenced by the European Union. However, the experience of Ireland's nearest neighbour, Britain, in introducing limited competition, privatization and a new regulator (OFTEL) during the 1980s also partly influenced the decision to develop an independent regulator for telecommunications in Ireland (Office of the Director of Telecommunications Regulation 2000: 1). Once established, the new regulator had to establish the nature and scope of its relationship with other actors in the regulatory environment, a process to which we turn here.

By virtue of the Communications Regulation Act 2002, the Commission for Communications Regulation or ComReg was founded on 1 December 2002, taking over from the Office of the Director of Telecommunications Regulation. It has remained as the sector regulator for general telecommunications and in performing its core task - the regulation of the electronic communications market in Ireland - it mirrors counterparts 
elsewhere in Europe. As will be identified below, however, since its establishment it has accumulated a growing number of ancillary tasks.

In introducing the legislation founding ComReg, the sponsoring Minister noted in the Senate:

It may be asked why we still need such regulation over three years after full liberalisation of the sector. The reason is that there are still substantial differences in market power between operators and competition could be inhibited if there was no regulatory framework in place. Some operators continue to be dominant and abuse of that dominant position needs to be prevented. (Seanad Éireann 2002, Vol. 169: Col. 988)

ComReg is a statutory body with its own corporate identity, distinguishing it in law from its parent department. One of the principal changes between it and its predecessor was in relation to its governing structure. While the ODTR had one person at its helm, ComReg is managed by three Commissioners, each appointed by the Minister following a public competition. The decision to appoint three Commissioners, according to the Minister, was in recognition of the fact that:

The [telecommunications] market is now changing with ever-increasing speed...in particular the convergence between telecommunications, broadcasting and IT sectors, evolution in technology and changes in user demand. (Seanad Éireann 2002, Vol. 169: Col. 990) 
In practice however, the Commissioners did not align with these three sectors.

Instead, as Figure 4.3 depicts, ComReg consists of four core Divisions (Retail and Consumer Services, Wholesale, Market Framework, and Corporate Services) supported by a Senior Legal and Senior Economic Advisors. Each Commissioner is appointed for a 3-5 year period and the role of Chair rotates between them on an annual basis. The Chair is in effect primus inter pares and has the casting vote in the event of a tied vote.

\section{$<$ insert figure4.3 around here $>$}

The role of ODTR had encompassed three areas: regulation of the electronic communications sector (telecom and broadcasting transmission systems), regulation of the postal sector, and management of the radio frequency spectrum.In practice, this work entailed such tasks as the development and implementation of a licensing regime for telecommunications operators in Ireland (including fixed, mobile and satellite operators); supervision of the interconnection regime in Ireland, dispute resolution among operators; licensing and regulation of television distribution systems, management and licensing of use of the frequency spectrum, and setting price caps on the major operator in the market where services were not competitive.

Many of ComReg's core function equate to those of the ODTR. Section 10 of its founding Act detailed the functions of ComReg. These included ensuring compliance by undertakings with obligations in relation to the supply of and access to electronic 
communications services, networks and associated facilities, managing the radio frequency spectrum, ensuring compliance by providers of postal services with relevant obligations, investigating complaints regarding the supply of and access to electronic communications services and networks, and compliance in relation to the placing on the market of telecommunications equipment.

Section 12 of the Act specified the objectives of ComReg in relation to telecommunications, namely, the promotion of competition, contributing to the development of the internal market, and promoting the interests of users. As well as providing and regulating the telecommunications sector, therefore, ComReg must also ensure efficient management of the radio frequency spectrum and provide a universal and affordable postal service ${ }^{5}$. In relation to radio frequency spectrum, as a non-landlocked and militarily neutral country, Ireland has considerable scope for utilizing its radio spectrum for the commercial market.

\subsubsection{Development of ComReg's powers}

In 2007, ComReg’s responsibilities and powers, as well as available enforcement measures, were substantially enhanced by the Communications Regulation (Amendment) Act 2007.In introducing the legislation, the Minister stated that:

The currentregulatory framework is based on competition law principles and aims to ensure fair competition between service providers, some of whom dominate for historical structural reasons. However, the evidence to date does not show the market to be moving towards a fully competitive state. ComReg's market 
analyses have found significant market power in both the fixed and mobile markets.

The Bill confers on ComReg competition law powers similar to that of the Competition Authority, so that it can investigate and prosecute restrictive agreements and practices, but only in regard to the communications sector. (Dáil Éireann, Vol. 632: Cols. 743-4, 27 February 2007)

Significantly, by virtue of the new legislation, ComReg no longer had to wait for a complaint of abuse of market dominance to undertake an investigation - it could now initiate such investigations itself. But perhaps the most important change in the 2007 Amendment was the fact that ComReg was granted competition powers in relation to electronic communications and services. As with the Competition Authority (below), if ComReg believes an undertaking has abused a dominant position, it must prove its case in the Courts. The Act therefore allowed the Commission to enforce both Irish and EU competition law in respect of issues including abuse of dominance and unsettled agreements.

Other important changes in the tasks and competences of ComReg arising from the 2007 Act included the new requirement to monitor the quality and efficiency of the emergency call answering service, the power to collect and disseminate information for the purpose of contributing to an open and competitive market, and granting to ComReg the power to demand from a person evidence or documents relating to any of the Commission's functions or objectives. Under the 2007 amending Act, ComReg must assess the various telecommunications markets in Ireland (as specified by the European Commission). Interviews identified that the publication of information on all specified 
markets annually in order to achieve EU targets had proved to be a very demanding task for ComReg. However, it has the power to designate other markets than those specified by the Commission.

ComReg must take the European Commission’s list of recommended markets and define product and geographic markets in accordance with the principles of competition law and national circumstance (Connery and Hodnett 2009: 243). Within the defined markets, ComReg may impose obligations on operators with Significant Market Power (SMP), but it must determine whether SMP exists and competition is therefore ineffective. In order to determine which regulatees have Significant Market Power (SMP), thresholds are determined by ComReg using a detailed market analysis procedure (Goggin 2009). Of particular importance in this process is the notification to the EU and other member states. Any subsequent comment following this notification is a formal process that contributes to the final decision of ComReg.

Interviews suggest that depending on the sensitivity of the issue, the European Commission may be notified earlier in the process about a forthcoming issue. Some of ComReg's staff have previously worked in the Commission, and bring to the organisation knowledge of the various procedures at EU level as well as contact points. This provides a first example of how informality, in this case through involvement in personal networks, plays a productive role in achieving a primary function of ComReg.

As might be expected, the operator designated as having SMP in several markets to date has been Eircom (Connery and Hodnett 2009: 247), though later reviews determined that they no longer held SMP in some (for example retail leased lines). Where Eircom retained SMP, a variety of remedies have been imposed including allowing 
competitors access to networks and infrastructure. Other operators such as Vodafone, $\mathrm{O} 2$, Meteor and 3 have been found to have SMP in markets concerned with mobile phones.

In line with EU Directives, ComReg operates an authorisation process for Electronic Communications Service and Electronic Communications Network providers that is they do not need a full licence to function but must let ComReg know of their intention to do so. Once a party has notified ComReg and completed the necessary documents, it is deemed to be authorised and added to ComReg's register of authorised undertakings (Connery and Hodnett 2009: 238-9).

However, under the Wireless Telegraphy Acts (1926-88), as well as complying with the conditions of the general authorisation, mobile phone operators and providers of fixed wireless services need to obtain a licence. Licences are normally required by very small or local operators such as pleasure craft operating short range radios or university radio stations among others. There are some exemptions for such licences, for example on aircraft.

ComReg is also required to determine the scope of the Universal Service Obligation (USO) for the Irish market and decide which undertaking(s) should be designated as the Universal Service Provider(s) (USP). In setting its USO obligations, ComReg is required to engage in a public consultation concerning the contents of the obligations, and the USP in Ireland is required to provide the USO services for a period of four years (ComReg 2006).

In order to further the various Universal Service Obligations, ComReg has developed a number of informal fora for engaging with various stakeholder groups, including a Consumer Advisory Panel and a Disabled Users Group. It also offers a 
number of websites to the public. These include a website which allows users to compare tariffs between operators (though interviews identified delays in updating its content to reflect changing tariffs and in accurate product comparisons). Another website provides consumers with information about making complaints and other general information in relation to mobile and land-based telecommunications, post and internet services.

\subsubsection{Complaints, Disputes and Mediation}

ComReg receives complaints from the public and from within the telecoms industry. There is no single format for submitting complaints, which can take the form of an e-mail or submission by a solicitor (Connery and Hodnett 2009: 272-3). ComReg is not bound to accept a complaint, and a 'compliance team' investigates the validity of complaints and assesses the impact on the market in order to allocate and prioritise resources. The compliance team can and does also undertake its own investigations. ComReg is obliged to keep confidential all information provided to it on that basis and there are statutory fines for the disclosure of information without the permission of ComReg to do so.

When evaluating the basis for progressing a complaint to an investigation phase, ComReg will need to get sufficient information to assess whether there is a potential regulatory or competition breach. In practice interviews identify that this is likely to require informal dialogue with the complainant unless the submitted complaint is comprehensive in terms of the scope and the legal basis. Internal guidelines exist to aid the relevant member of compliance team when investigating a complaint that has been received externally or one that ComReg has started on its own initiative. The compliance function can be considered to cover a number of phases, encompassing a pre-study phase, 
a feasibility phase, an execution phase (which is subdivided into three stages, investigation, compliance and enforcement) and a conclusion phase at which time the relevant parties will be informed of the decision. Considerable emphasis has been put on transparency in this process with new guidelines and procedures being published in 2010 following consultations.

Where a dispute occurs between two undertakings, ComReg can be requested by either party to investigate the dispute with a view to making a determination. Once a dispute notice has been received, ComReg decides whether the criteria necessary for a dispute submission have been received and on the appropriate course of action as set out in its Dispute Resolution Procedures published in 2010. The compliance team (above) are also responsible for disputes and the decision is fed back to the parties involved in the way of a Final Determination. Failure by an undertaking to comply with a determination constitutes an offence.

As well as formal dispute resolution procedures, disputes are resolved through informal contacts or negotiation; within industry fora or by means of an alternative intermediary. ComReg chooses the most appropriate mechanism on a case by case basis and bears the costs associated with the provision of any mediation service. If mediation is agreed to, ComReg appoints an independent external mediator or ComReg official within ten days of that agreement. ComReg can also offer mediation in the case of a cross border dispute, where National Regulatory Authorities jointly decide that it would resolve the dispute in a timely manner.

\subsubsection{ComReg’s autonomy}


The three Commissioners of ComReg are formally appointed and can be dismissed by the Minister, but in day to day operational terms are considered to be independent of him/her. The Commissioners cannot hold any other office in government, and independence is a formal requirement for appointment. A Commissioner can hold office for a maximum of two 5-year terms and their remuneration is fixed by the Minister with the consent of the Minister for Finance. Also, in order to underline their autonomy, Commissioners do not receive an annual bonus from the Minister.

To date, the issue of market credibility has been central to the development of ComReg and to this end its autonomy has extended to its internal management. It enjoys considerable freedom with regards to the management of its personnel, and can make individual decisions regarding all management decisions, including appointments and terminations. However, it is still bound by general rules regarding personnel management decisions, and the embargo on public service recruitment introduced in 2009 and subsequent levies on public service pay apply to it.

Financial management autonomy is also high: ComReg can freely shift its budget allocation within the year, and may take out loans and set tariffs for services or products, but is confined by general rules set by the department of Finance for example on issues of procurement. Section 29 of the 2002 Act states that ComReg may borrow money but only with the consent of both the parent Minister and the Minister for Finance. ComReg's primary source of income comes from spectrum fees, levies and licenses which comes directly to them. Such income may exceed the requirements of ComReg and if so it makes a contribution to the Exchequer. The relatively high level of managerial autonomy enjoyed by ComReg was evident in its awarding of bonuses to senior staff in 2011 (other 
than Commissioners, and as part of a performance-related pay scheme) when such schemes had been suspended in other public organizations ${ }^{6}$.

ComReg has a variety of regulatory instruments at its disposal when carrying out its functions and in particular when seeking to address SMP. These include imposing obligations of transparency, non-discrimination, access, accounting separation and price control (Connery and Hodnett 2009: 247). As in other countries, the most important of its regulatory tools are the use of price and tariff regulation, the prior approval of market activities by regulatees (as well as the requirement by them to allow network interconnection and provide access to infrastructure to other regulates), the achievement by regulatees of minimum standards, and adherence to universal service obligations. Another core tool in ComReg's work is the definition of the reserved telecoms market, which leaves the remainder open to general competition law. It also places considerable weight on the publication of information for consumers. Less emphasis is placed on the use of formal competition law, even though it has been provided with such statutory powers (and cooperates with the Competition Authority as necessary) and setting mandatory standards. It also monitors changes in corporate structure and conduct within the market. Investment and maintenance of telecoms infrastructure is also monitored by ComReg.

Alongside these formal expressions of autonomy, however, interviews reveal that ComReg also utilizes informal means to pursue its goals. For example, it is in regular informal contact (e-mails and telephone calls) with its parent Department, as well as the Department of Finance which has an oversight role in respect of all statutory and publicly funded organizations. The use of such communications is considered to be integral to the 
regulator's work, and has the added benefit of reducing transaction costs and fostering trust between actors in the regulatory regime. At no stage is ComReg's decision-making autonomy in question, however. Rather, the interviews suggest that these communications help to determine boundaries in the constantly changing regulatory environment.

\subsubsection{ComReg’s control}

As outlined above, while ComReg enjoys considerable autonomy in the performance of its work and internal operations, there are a number of controls to which it is subject and which can limit this freedom of action. Many of these are routine. For example, with regards to ex ante control, the framework of the goals of the organization is already set in its document of establishment, the 2002 Act. Under Section 9 of the 2007 Amendment, the Commission also has to produce an Action Plan every year, detailing targets in its strategy for the next year. This Action Plan is made after consultation with the Department under the authority of the Minister. In the financial area ComReg has an Audit Committee, of which a majority of members are external to the organisation. It must provide an audit compliance statement with its annual report and is audited by the state's auditor, the Comptroller and Auditor-General. ComReg must also appear before relevant parliamentary committees concerning their financial and policy responsibilities (though the latter is not considered in a systematic manner by the committees). There is no constitutional or legal requirement on a Minister to implement the views of a parliamentary committee. 
In the area of policy, however, the picture is more complex. In conducting its work, Section 12 (4) of the 2002 Act requires ComReg to 'have regard to policy statements, published by or on behalf of the Government or a Minister of the Government and notified to the Commission, in relation to the economic and social development of the State.' Thus the absolute autonomy of ComReg can technically be curtailed by its parent Minister, though these directions can be subjected to public consultation prior to their issue. The Minister must also make his or her intentions known by providing the Direction to ComReg and also publishing it. A period of 21 days is provided for submissions to be made on the direction. An example of this occurred in 2003 when the Minister released a number of policy directions to ComReg, including the introduction of flat rate internet access and the provision of monthly progress reports on the delivery of such access to customers. However, in practice the Minister tends not to issue them and there is only one other occasion in which it has occurred. This was in 2004 when a package of directions concerning network roaming, pricing and interconnection were issued. The legislation prevents the Minister from making any directions in respect of individuals or individual undertakings.

Though ex ante control is thus limited, it must be emphasised that the legislative mandate of ComReg, as a state agency, can at any time be amended by the Government. Indeed Gorecki (2011) argues that recent initiatives by the Irish government in 2010 to seek more accountability, transparency and performance assessments from regulators, as well as greater political input into decisions and priorities, runs counter to the dynamic of regulatory autonomy and poses a threat to the independence of regulators. He argues that any new legislation that seeks to co-ordinate the work of regulators in order to achieve 
national economic goals requires carefully balancing the means to achieve such goals with the current statutory mandates of the regulators. He proposes that while some of these developments may indeed enhance the regulatory regime in Ireland, they may alternatively present conflicting demands on regulators, lead to over-emphasis on shortterm rather than long-term goals, and ultimately raise uncertainty in those market sectors where certainty is an integral part of development. The Programme for Government of the administration that took office early in 2011 also issued intentions in relation to ComReg's decision-making, stating that in relation to liberalization of postal services, it would:

[...] protect universal service obligation by assigning it to An Post for at least 20 years, make provision for state subvention and require that any decision by ComReg to reassign or scrap USO is subject to ministerial approval. (Government of Ireland 2011).

Ex post, there are several devices in which both the overall functioning and specific decisions of ComReg can be reviewed. Section 6 of the 2007 Amendment states that the Minister can request information from ComReg concerning the technical operation or performance of electronic communications networks and infrastructures in the State. Also, the Minister meets with Commissioners every one-two months to discuss goals (see below). These are formal and high-level meetings. However they are supplemented by more frequent formal and informal interactions at a lower level that is between departmental officials and the staff of ComReg. As with other informal 
communications identified above, such meetings act as a means to supplement the formal mechanisms in place in order to achieve specific goals.

Appeals against ComReg decisions are not made by another regulator. Instead, they are taken by operators who appeal in the first instance to the Commercial Division of the Court, also known as the Commercial Court. In relation to such appeals by operators, there have been several incidents which resulted in operators taking legal action. Two cases which ended up in the Supreme Court achieved particular prominence. The first concerned the awarding of the third GSM licence to Meteor in 1998. The award was unsuccessfully challenged in the Irish High Court and Supreme Court by the losing party Orange and it was not until 2001 that Meteor began operating. The second case arose in 2008 when Eircom lodged an appeal with the Irish High Court against a decision by ComReg to cut the cost of line sharing in a bid to make its local loop network more competitive for other operators. This case was significant as Eircom argued that it had no right of appeal in a case where it was directed by ComReg to do something that could not be undone within the period available for an appeal. They argued that the decision of ComReg was in contravention of Article 4 of the Framework Directive which set out an unqualified right of appeal (Connery and Hodnett 2009: 473). The case was won by Eircom.

Interviews suggest that telecoms operators have engaged in strategic behaviour when deciding on whether or not to pursue legal appeals against decisions of ComReg. It was also suggested that the duration of court cases are taken into account. These tend to take between 6 months and a year to resolve, though in some cases they have lasted longer than a year. Strategic behaviour by regulatees is not new in the telecoms sector. 
Indeed, when ComReg's predecessor the ODTR was first established, any appeals filed by regulatees to it meant automatic suspension of any related decisions, and it required a change in the law in 2001 to ensure that decisions were no longer suspended on appeal.

It is also the case that ComReg has no power to levy significant administrative fines, powers which most other EU regulators have. ComReg therefore faces a choice of imposing very small fines or else pursuing a matter further through the courts with a view to demanding higher fines, with no guarantee of success.

\subsection{Formal and informal interactions in the regulatory arrangement}

Having considered in some detail the role, autonomy and control of the principal actor in the Irish telecoms regulatory arrangement, we turn here to consider the other actors - The Competition Authority, the Broadcasting Authority of Ireland, the Department of Communications, Energy and Natural Resources and the Courts (see figure 4.4). In each case their formal role is described and then their relationship with ComReg. Again, we find that in almost all cases, informal as well as formal communications and processes form an important part of these relationships.

\section{<insert figure4.4 around here $>$}

\subsubsection{The Competition Authority}


The Competition Authority (TCA) was established in 1991 to enforce general EU and Irish competition law, to review large mergers, and promote competition within the Irish economy. It therefore has jurisdiction in relation to the telecommunications market and the application of competition law within it. Its relationship with ComReg has developed from being a largely informal one to one described in law. Currently, both TCA and ComReg are jointly responsible for administering and enforcing the Competition Act 2002 in the electronic Communications sector, as specified in the Communications Regulation (Amendment) Act 2007. This formal sharing of co-competition powers in the sector emerged in order to resolve issues of overlapping jurisdictions between both regulators (below).

TCA has a single chairperson formally appointed by the Minister (following a selection process), and its legislation specifies a list of grounds under which the Minister can remove him/her from office. The chairperson, along with their directors, forms the management Board of TCA. This group has decision-making (as opposed to advisory) functions and has the authority to impose fines (though this authority has never been tested in the courts) ${ }^{7}$. While TCA is independent of the Department in carrying out its functions, the Minister retains certain powers, including the right to direct TCA to carry out a study. Also, media mergers require the approval of the Minister.

The work of TCA is determined by its 3-year strategy statement and its related annual business plans. These documents are forwarded to the Minister but the Authority retains the autonomy to formulate its own goals and evaluates its own performance. There are no formal reporting requirements although the Authority appears before and is accountable to parliamentary committees. 
When the ODTR was created in 1997, there was no statutory provision for interaction or co-operation between the two organisations. Both had obligations in relation to protecting commercially confidential information and in the absence of a legal framework for such, no information could be exchanged. However, at an informal level, the ODTR and the Competition Authority met regularly to discuss issues of general interest and common concern. The development of this informal relationship was augmented by the signing of a Memorandum of Understanding between the two offices. In the development of new competition legislation in 2002, provision was made for formalising the relationship between the two regulators. Specifically, it obliged the Competition Authority to enter into co-operation agreements with a number of NRAs. These agreements were to focus on facilitating co-operation and confidential information exchange, as well as to avoid duplication of efforts.

In 2002, ComReg and the Competition Authority signed a 'co-operation agreement' to facilitate co-operation, avoid duplication of activities and ensure, as far as practicable, consistency between decisions made or other steps taken by the parties relating to competition between undertakings in the telecoms market. While the agreement was a first step in providing for greater co-operation, amending legislation allowed the opportunity to put the relationship on a statutory footing. In 2007, the Communications Regulation (Amendment) Act 2007 (see above) came into force and as well as granting ComReg some competition powers, it set out when and how ComReg and the Competition Authority should co-operate. As well as this formal requirement for interaction, however, informal communications and contacts are still an essential part of the relationship between ComReg and TCA. 


\subsubsection{Broadcasting Authority of Ireland}

In Ireland, radio and television broadcasting content is regulated by the Broadcasting Authority of Ireland (BAI) which was established in October 2009. The BAI took over the functions of its predecessor the Broadcasting Commission of Ireland, as well as the functions of the Broadcasting Complaints Commission and certain self-regulating powers of the governance boards of the national broadcasters Radio Telefís Éireann and Téilifis na Gaeilge (an Irish language television station). The BAI has a CEO appointed by a Board, after consultation with the Minister for Communications, Energy and Natural Resources. The objectives of the BAI include ensuring variety in the categories of broadcasting services available and ensuring rights of expression are upheld. Amongst the BAI's powers is the ability to fine broadcasters for contract breaches rather than necessarily removing their contracts.

The BAI is required to consult with the Minister and its parent Department on a regular basis, and as well as its founding legislation it has a strategic plan approved by the Department and Minister on which its work is based. Goals are therefore set after consultation with the Department, which also evaluates the work of the BAI. It reports on its work each trimester. As with the case of ComReg, under its founding legislation, the Minister 'may issue such policy communications to the Authority as he or she considers appropriate to be followed by the Authority in the performance of its functions' and the Authority must take these into consideration when making its decisions (Broadcasting Act 2009: Section 30). BAI is funded primarily through funds from regulatees, but also in return for services rendered and through some minor commercial activity. 
Under Section 26 of the 2009 Act, one of the principal functions of the BAI is to 'liaise and consult with the Communications Regulator in the preparation of the allocation plan for the frequency range dedicated to sound and television broadcasting'. Technological innovation and convergence in relation to audiovisual content have also placed pressures on the broadcasting sector. As ComReg has responsibility for managing radio spectrum, there is a formal relationship between BAI and ComReg in relation to the granting of licences for commercial broadcasting. With the increased convergence of telecom and broadcasting technologies, ComReg's engagement with the BAI has become increasingly important. Survey information obtained for the development of this chapter identify that again ComReg engages in regular informal communications with BAI, and that this level of communication has increased to almost a daily basis. In late 2011 the new administration announced its desire to merge ComReg with BAI as part of a wider programme of state agency reform.

\subsubsection{Department and Minister for Communications, Energy and Natural}

\section{Resources}

The Department of Communications, Energy and Natural Resources is one of sixteencurrent government departments, each of which is headed by a Minister. As noted above, as each Minister is constitutionally and legally responsible for the activities of his or her department, and all activities of the department are conducted in the name of the Minister, there is rarely policy divergence between the Minister and his/her Department; the Minister is the decision-maker. The most senior civil servant in each Department is 
the Secretary-General, who works closely with the Minister and who has particular responsibility for the proper management of financial affairs in the Department.

The Minister is also responsible to parliament for any agencies or offices under the aegis of his/her Department, and state funding for such organizations normally comes through the Department, who also audit and oversee their work. Apart from corporate units, the Department of Communications, Energy and Natural Resources has a number of operational sections. The Communications Section is the main point of contact for ComReg (though it also communicates regularly with the Broadcasting Section). The key role of this section is the development of effective policies for the regulation of the electronic communications sector, and management of the radio frequency spectrum. Responsibility for the implementation of policies rests with ComReg which, as detailed above, is normally independent in the exercise of its regulatory functions.

As noted above, ComReg's Commissioners meet with the Minister several times annually to discuss any and all matters within ComReg's remit. These meetings, as well as its appearances before Oireachtas committees (which also occur on several occasions during the year) are of central importance to its work. Rather than a form of evaluation or assessment of performance, these meetings tend to be concerned with planning future policy direction and objectives. Interviews recognise the important role played by the Minister (and the Government generally) in setting ComReg's policy agenda, and the requirement to have a strategy statement every two years combined with annual action plans and budgets means that communications with the Department are necessarily frequent. Informally, these meetings may be considered a form of strategy statement review but they are not evaluations. Other meetings occasionally take place as necessary 
(normally several times per year) between ComReg and Ministers and officials from ‘central' Departments (Finance and Taoiseach, and since 2011 the Department of Public Expenditure and Reform), and also with other regulators such as the Competition Authority and the National Consumer Agency.

In terms of ComReg's ability to influence policy making within its parent Department, interviews suggest that this is largely an informal process. In particular, the technical nature of much of telecommunications policy means that the Department seeks and receives the assistance of ComReg when developing its policy and will be guided by ComReg's opinion on best practice in relation to such matters as availability, quality of service and other standard setting. ComReg is not statutorily required to do so. There are number of areas - such as the allocation of radio frequency spectrum - where ComReg has the necessary mandatory powers and does not require Departmental approval. Also, while responsibility for the transposition of EU Directives and Regulations pertinent to telecommunications formally lies with the Department, interviews identify that ComReg assists it in its determination as to whether transposition must be conducted through primary or secondary legislation (the latter being less onerous). A member of staff in ComReg has responsibility for monitoring the transposition process to ensure that Ireland and ComReg is compliant with EU law, and is in regular communication with the Department. ComReg also assists the Department in its engagement on telecommunications policy at various EU fora (below).

\subsubsection{The Courts}


The Irish Constitution provides that 'justice shall be administered in courts established by law'. Apart from the courts of local and limited jurisdiction (the District and Circuit courts), the State's two superior Courts of Appeal are the High Court and the Supreme Court. Due to the growing number of cases relating to commercial law, a Commercial Court was initiated in 2004. It operates as a separate division within the High Court, thus reducing the burden of work within that court. Almost all cases concerning telecoms and telecoms regulation are now dealt with by the Commercial Court. There is no telecoms Ombudsman in Ireland. As noted above, a number of high profile cases have been decided by the Courts.

The 2002 Regulatory Framework also required all Member States to have an effective appeals mechanism. In 2003, and following EU requirements for an appeals forum, a three-person quasi-judicial Electronic Communications Appeals Panel (ECAP) was created in Ireland to allow operators appeal ComReg decisions. Decisions by ECAP could be further appealed to the Irish Courts and the European Court of Justice. In practice, the proliferation of appeals against regulatory decisions, delays in hearing them, and the decision of operators to bring decisions of ECAP to the courts led to its abandonment as a mechanism in 2007. ComReg supported this decision but interviews suggest that some major operators did not. A review of the regulatory environment in Ireland published in 2009 noted that the decision to abolish ECAP was perhaps questionable given that it had heard only two substantive cases (Economist Intelligence Unit 2009: 130).

The current mechanism for appeals against decisions by ComReg is therefore the High Court $^{8}$ (or more specifically the Commercial Court which hears the commercial 
cases appealed to that Court), and a subsequent appeal may be lodged with the Supreme Court. Interviews suggest that ComReg normally appears in the Commercial Court 4-5 times per year, though the costs of doing so can vary considerably. The European Court of Justice is a final avenue of appeal for operators ${ }^{9}$. Interviews also suggest that ComReg uses its remit and influence to try and resolve disputes between regulators as well as to avoid disputes reaching the Courts. As a result, a number of cases have avoided full judicial proceedings. There is no evidence that informality plays a part in ComReg's relationship with the Courts.

\subsubsection{ComReg and its Regulatees}

To complete the picture of the Irish telecoms regulatory arrangement, it is important to note the various fora through which ComReg communicates with regulatees and EU actors. ComReg routinely meets with a body known as the Telecommunications and Internet Federation (TIF), which is a sub-committee of a large interest group known as the Irish Business and Employers Confederation (IBEC). The TIF represents operators working in the field of electronic communications. While these meetings provide an opportunity to engage on matters of concern to the sector, ComReg's Commissioners also meet with the CEOs of individual undertakings to discuss concerns.

In relation to regulatee or industry 'capture', ComReg seeks to avoid capture by the industry (producer) rather than the consumer, or by any individual producer in the sector. In relation to the first dimension, ComReg has initiated a Consumer Advisory Panel and conducts regular consumer surveys. ComReg monitors calls to its customer call centre to identify what the changing trends are in the market. In relation to capture by 
any one regulatee, and in particular the incumbent, ComReg meets regularly with another umbrella organisation known as the Alternative Operators in the Communications Market $(\mathrm{ALTO})^{10}$ and the European Competitive Telecommunications Association (ECTA). As required by the EU regulatory framework, ComReg insists it is 'technology neutral' in relation to service development. Interviews confirm that ComReg has traditionally met most frequently with Eircom, and mainly to discuss USO-related issues, but this is largely due to the fact that as the incumbent operator, it has more obligations to fulfil in the market than other operators.

Rather than adopting formal regulation in all cases, ComReg has on occassion sought to encourage voluntary changes in behaviour by regulatees in some aspects of the market. A prominent example of this occurred in respect of mobile termination rates, where, prior to the European Commission's issuance of a Termiantion Rate Recommendation in 2009 to be followed by national regulators, ComReg had negotiated voluntary reductions in charges between operators. The Commission issues their Recommendation out of concern that a common EU approach to the matter was not emerging.

\subsubsection{ComReg and the EU}

ComReg's engagement with the institutions of the EU is similar to that of other country case-studies presented in this volume, and it engages directly with various EU regulatory fora several times per year. For the purposes of its work, its engagements with the Commission, the IRG/ERG and the Radio Spectrum Policy Group are particularly important. These meetings are usually concerned with data exchange and agreement on 
common policy positions. Of increasing importance is its input to the Body of European Regulators for Electronic Communications (BEREC). It also meets with the European Telecommunications Network Operators Association (ETNO), ECTA and the Confederation of European Posts and Telecommunications (CEPT) several times per year. In relation to the EU's Communications Committee (Cocom), Ireland is represented by the Department of Communications, Energy and Natural Resources but informally, ComReg assists the Department in the performance of this role. Similarly, ComReg is able to indirectly feed into meetings of the Council via its parent Department, to whom it presents informal consultation on relevant matters that arise.

\subsection{Conclusions}

The examination presented here has focused on the work of the main sectoral regulator ComReg - within the Irish telecommunications regulatory arrangement. In pursuing its mandate and engaging with a wide variety of stakeholders, the study identifies the importance of informal as well as formal relationships and practices. From the use of personal contacts at the EU level, to regular informal communications with other NRAs and its parent Department, to establishing non-statutory fora with stakeholders, ComReg has sought to deploy 'softer' forms of influence to supplement its formal requirements and statutory powers. This presents the Irish case in contrast to the other country studies presented here, where there are more complex formal relationships and modes of communication within the regulatory environment.

Returning to the two-dimensional conception of informality adopted at the beginning of the chapter - the use of discretion in the implementation of policy, and the 
engagement of actors in non-formal (but rule-bound) networks and communications - the Table below identifies how these are manifested in the Irish case by drawing on the findings above.

\section{<insert table4.1 around here>}

In all cases, the use of informality does not undermine or supplant the formal modes of operation and communication. Rather, it supplements them by determining respective roles and responsibilities within what one interviewee referred to as the regulator's 'legislative tramlines’. Thus while informality may not be institutionalized in the sense of offering an alternative to formal regulatory rules, it can instead be viewed as complementary to the statutory framework.

It is not surprising of course that a regulatory authority would employ discretion in the pursuit of its mandate, but the engagement in non-formal networks and communications is quite extensive and in keeping with a core feature of Irish administrative culture. Of particular interest is the development of the relationship between ComReg and the Competition Authority, which involved previously informal practices and procedures later becoming formalized in law. However informal communications between the two actors remain important in regulating of that market sector.

The engagement of ComReg is multiple and various networks (including those they have deliberately created) supports strongly Hood's concept of Nodality as identified in the introduction as a means of achieving tasks. It also fits with Ayres and 
Braithwaite's concept of negotiated modes of regulation which are contrasted with more adversarial and litigious forms of regulatory enforcement. In the Irish case, we find that ComReg's use of informal communications in the mediation of disputes and conflicts has been important for the development of the Irish regulatory regime by establishing boundaries where they have not been formally delineated. Understanding the de facto independence of the regulator in the Irish telecoms regulatory arrangement therefore requires moving beyond formal frameworks and rules to recognising the role played by non-formal and informal activities.

In conclusion, the convergence of technologies in the broadcasting, media and telecommunications arenas, as well as the desire to Irish governments to rationalize structures and practices within the bureaucracy as a response to the financial crisis will ensure that the regulatory arrangement for telecoms will continue to evolve. The proposed merger of ComReg and BAI will also alter the shape of the regulatory regime. EU pressures for greater harmonization in telecommunications policy within the single market (as part of the Digital 2020 initiative), as well on-going exchanges between national regulators through BEREC, will undoubtedly promote standardization in practices. Also, the enduring dominance of incumbent operators and SMP in a number of telecoms markets determines the need for robust national regulatory regimes. The extent to which these pressures will encourage or reduce the use of informal practices and networks of engagement within the Irish case remains to be seen and should provide the basis for fruitful future analysis. 